\title{
Molecular presence of Felis catus gammaherpesvirus -1 in cats with ocular disorders in Turkey
}

\author{
Bahattin Taylan KOÇ,a, ${ }^{1, \mathbb{M}}$ Më AKKARTAL ${ }^{2, b}$ \\ ${ }^{1}$ Aydın Adnan Menderes University, Faculty of Veterinary Medicine, Department of Virology, Aydın; ${ }^{2}$ Nova Veterinary Clinic, \\ Balıkesir, Turkey. \\ aORCID: 0000-0002-4279-6233; ' $\mathrm{ORCID:} \mathrm{0000-0002-1499-7652}$
}

Received date: 03.04.2020 - Accepted date: 17.06.2020

\begin{abstract}
Felis catus gammaherpesvirus-1 (FcaGHV-1) is a newly discovered feline virus, and its effects on the health of cats are not certainly known. Known feline viruses play a huge role in ocular disorders in domestic and wild cats. Also, emerging viruses may be responsible for ophthalmic diseases of cats. We aimed to investigate the presence of FcaGHV-1, Feline calicivirus (FCV), Feline herpesvirus -1 (FHV-1), Feline immunodeficiency virus (FIV), Feline infectious peritonitis virus (FIPV), Feline leukemia virus (FeLV), Feline panleukopenia virus (FPV) in cats in Turkey by molecular methods, and to examine the relationship between the virus and ocular disorders by obtained data. Swab, blood and biopsy samples were collected from 45 owned cats with ocular disorders. Molecular techniques including viral genome amplification and sequencing were used in this study. Two out of 45 cats $(2 / 45 ; 4.4 \%)$ found to be FcaGHV-1 and FIV positive. Our two sequences and a reference sequence from Japan (LC437925) have constructed a separated subgroup in the molecular phylogenetic tree. In this study, we have not found a close relationship between ocular disorders and the presence of FcaGHV-1. This is the first study exhibiting the presence of FcaGHV-1 and its molecular status in Turkey. Acquired knowledge suggests performing further studies on FcaGHV-1.
\end{abstract}

Keywords: Cats, gammaherpesvirus, molecular, ophthalmic, phylogeny.

\section{Türkiye'de oküler bozukluğu olan kedilerde Felis catus gammaherpesvirus -1'in moleküler varlığı}

Özet: Felis catus gammaherpesvirus-1 (FcaGHV-1), kedilerin sağlığı üzerindeki etkileri bilinmeyen yeni keşfedilmiş bir kedi virusudur. Bilinen kedi virusları, evcil ve vahşi kedilerdeki oküler bozukluklarda büyük rol oynamaktadırlar. Ayrıca, yeni ortaya çıkan viruslar kedilerin oftalmik hastalıklarından sorumlu olabilir. Bu nedenle hem Türk kedilerinde FcaGHV-1, Feline calicivirus (FCV), Feline herpesvirus -1 (FHV-1), Feline immunodeficiency virus (FIV), Feline infectious peritonitis virus (FIPV), Feline leukemia virus (FeLV), Feline panleukopenia virus (FPV) varlığını moleküler yöntemlerle araştırmayı, hem de virus ve oküler bozukluklar arasındaki ilişkiyi elde edilen verilerle incelemeyi amaçladık. Swap, kan ve biyopsi örnekleri, oküler bozukluğu olan 45 kediden toplandı. Bu çalışmada viral genom amplifikasyonu ve sekanslama dahil moleküler teknikler kullanılmıştır. 45 kediden ikisinde (2/45; \%4,4) FcaGHV-1 ve FIV pozitif olarak bulundu. İki sekansımız ve Japonya'dan bir referans sekans (LC437925), moleküler filogenetik ağaçta ayrı bir alt grup oluşturmuştur. Bu çalışmada, oküler bozukluklar ile FcaGHV-1 arasında sıkı bir ilişki saptanmamıştır. Bu, Türkiye'de FcaGHV-1 varlı̆̆ını ve moleküler durumunu gösteren ilk çalışmadır. Edinilen bilgi, FcaGHV-1 hakkında daha fazla çalışma yapılmasını önermektedir.

Anahtar Kelimeler: Kediler, gammaherpesvirus, moleküler, oftalmik, filogeni.

\section{Introduction}

Ocular diseases caused by feline viruses are frequently observed in domestic cats. Clinical manifestations can occur in many variable forms including chemosis, epiphora conjunctivitis, keratitis, keratoconjunctivitis, uveitis, etc. Viruses can be either the main factor or cofactor for these ocular disorders $(9,10$, 13, 19, 23). Feline herpesvirus-1 (FHV-1) and Feline calicivirus (FCV) are more prominent agents compared to other viruses causing ocular infections $(9,13,23)$. FHV-1 belongs to the genus of Varicellovirus, the subfamily of Alphaherpesvirinae, the family of Herpesviridae (13). FCV is taxonomically classified in the genus of Vesivirus, the family of Caliciviridae. Both are highly contagious viruses and cause respiratory and ophthalmic infections in felids $(10,13,23)$.

Other feline viruses, such as Feline immunodeficiency virus (FIV), Feline leukemia virus (FeLV), Feline 
panleukopenia virus (FPV), and Feline adenovirus (FAdV), may also cause similar ocular symptoms, in addition to their specific symptoms $(9,19,23)$. However, these agents are less important compared to FHV and FCV for ocular disorders. Mostly, mentioned agents can be the cofactors for FHV-1 and FCV. Especially, FIV and FeLV are immunosuppressive agents for cats, which can be the underlying essential factors in some ocular disorders by other relevant agents $(9,19,23)$. In addition to all these, emerging viruses might have been already acting an efficient role in ocular infections due to their pathological reflections, that have not been unknown.

Felis catus gammaherpesvirus -1 (FcaGHV-1) is a recently discovered virus in domestic cats (2). FcaGHV-1 is classified in the genus of Percavirus, the subfamily of Gammaherpesvirinae, the family of Herpesviridae $(2,4)$. FcaGHV-1 is claimed as a novel virus that might cause immunosuppressive symptoms in cats in studies that have been conducted so far, although it has been assumed as asymptomatic in the early stage of discovery (2-4, 15-18, 24). There have already been some studies on its presence, epidemiology, prevalence and comparison to risk factors in various countries $(2-4,15-18,24)$. However, the interaction of the ocular system and FcaGHV-1 has not been specifically considered.

In this study, we hypothesized that FcaGHV-1 would be responsible for ocular infection in case of the absence of FHV-1 and FCV. Accordingly, we have intended to investigate the molecular presence of FcaGHV-1 and its related phylogenetic analysis, in addition to other viral agents (FHV-1, FCV, FIV, FIPV, FeLV, FPV) in clientowned cats with ocular symptoms in Turkey.

\section{Materials and Methods}

Sampling: In this study, conjuctival swabs, whole blood, and biopsy samples have been collected from 45 clinically symptomatic cats had at least an ocular disorder including corneal opacity, conjunctivitis, keratoconjunctivitis, chemosis, epiphora, symblepheron in 2019. The biopsy samples, including different parts of the eye - globe, conjunctiva, were only taken from operated cats during operation by veterinary ophthalmology surgeon. Individual properties were recorded by declaration and approval of the client during sample collection. All samples from the vet clinics in Balıkesir and Aydın were stored at $-20^{\circ} \mathrm{C}$ during transport to Aydın Adnan Menderes University Faculty of Veterinary Medicine Department of Virology laboratory.

Molecular detection analysis of feline viruses: Nucleic acids from all samples were isolated using the method of "Phenol:Chloroform:Isoamyl Alcohol (25:24:1)" as described by Chomczynski and Sacchi (5).
Reverse transcriptase-polymerase chain reactions were conducted to each isolated RNA, belonging to FCV and FIPV according to kit producer's protocol (RevertAid, First Strand cDNA Synthesize Kit, Thermo ${ }^{\circledR}$, USA). Isolated DNAs and obtained cDNAs were kept at $-80{ }^{\circ} \mathrm{C}$ until molecular analyses, and densities of nucleic acids were measured by nanodrop (Thermo Scientific ${ }^{\mathrm{TM}}$ NanoDrop ${ }^{\mathrm{TM}}$ One, CA, USA) immediately before polymerase chain reaction. In polymerase chain reactions, different primer sets, previously reported, were used to amplify specific partial gene regions belonging to each mentioned virus (Table 1). PCR conditions were optimized and performed according to the suggested protocol by the recombinant enzyme manufacturer (VitaProof $^{\circledR}$ Polymerase, Procomcure, Austria). PCR products were run in $1 \%$ agarose gel in "Tris:Acetic Acid:EDTA" solution under electrophoresis. Amplified products were screened under blue light transilluminator.

Phylogenetic analysis of FcaGHV-1: Novel FcaGHV-1 gB partial sequences were cleaned from noisy and error readings using Tracer software implemented in a molecular and phylogenetic analysis tool, MEGA X (11) after sequencing process. Cleaned sequences and other reference sequences from GenBank were aligned by using MEGA X (11). A maximum-likelihood tree was conducted by estimating based Kimura-2 parameter and 1000 bootstrap replicates.

\section{Results}

We have not detected any positivity in terms of FCV, FHV, FIPV, FeLV, and FPV. Two out of 45 cats with ophthalmic symptoms were detected both FcaGHV-1 positive $(2 / 45 ; 4.4 \%)$, both also FIV positive. We have obtained amplified products in the length of $350 \mathrm{bp}$. and 859 bp. for FcaGHV-1 and FIV, respectively. Of two dual infection cases (FIV/FcaGHV-1), in the first one, a cat, named "Şirine", exhibited the worst clinical condition compared to other cats in the study (Figure 1). This cat is one-year old and female. Chemosis, blepharospasm, symblepheron, and deep corneal ulcers were observed in clinical examination and the cat suffered by both the pain and physical limitation. The eyes of cat "Şirine" were operated to relief by an ophthalmology surgeon and a conjunctival biopsy material was taken to investigate the presence of mentioned viruses (FcaGHV-1, FHV, FIV, FCV, FIPV, FeLV, and FPV) during operation. After the first operation, as a complication, conjunctival tissue had covered on the corneal surface. Conjunctival tissue was excised using the keratectomy method as a second operation after the active symptomatic period. Another cat named "Sokak Kedisi" was male and two-months old and had corneal ulcer and conjunctivitis in clinical examination. 
Phylogenetic analysis of FcaGHV-1 was conducted with downloaded sequences from GenBank. After phylogenetic tree construction, sequences cumulated on two main separated branches which have been colored purple and blue (Figure 2). Both Turkish FcaGHV-1 sequences found to be close to 4484 from Japan (LC437925). These three strains constituted a separate subgroup which had $93.5 \%$ similarity rates to other taxa in purple colored cluster (Figure 2).

Table 1. Primer sets used for this study.

\begin{tabular}{|c|c|c|c|c|}
\hline Virus & Primer ID & Sequence $\left(5^{\prime} \rightarrow 3^{\prime}\right)$ & Target gene & Ref. \\
\hline \multirow{4}{*}{ FIV } & VE-1S & GAGTAGATACWTGGTTRCAAG & \multirow{4}{*}{ env } & \multirow{4}{*}{ (7) } \\
\hline & VE-1R & CATCCTAATTCTTGCATAGC & & \\
\hline & VE-2S & CAAAATGTGGATGGTGGAAY & & \\
\hline & VE-2R & ACCATTCCWATAGCAGTRGC & & \\
\hline \multirow{2}{*}{ FHV-1 } & FH737-f & GCACACGACCGGCTAATACAGG & \multirow{2}{*}{$\mathrm{gB}$} & \multirow{2}{*}{$(26)$} \\
\hline & FH737-r & CAGCTTTCGAGAGGCACATACCC & & \\
\hline \multirow{2}{*}{ FCV } & $8 \mathrm{~F}$ & CACSTTATGTCYGACACTGA & \multirow{2}{*}{ C (capsid) } & \multirow{2}{*}{ (10) } \\
\hline & $8 \mathrm{R}$ & CTRGADGTRTGCARRATTT & & \\
\hline \multirow{2}{*}{ FIPV } & 212 & TAATGCCATACACGAACCAGCT & \multirow{2}{*}{ M } & \multirow{2}{*}{$(22)$} \\
\hline & 1179 & GTGCTAGATTTGTCTTCGGACACC & & \\
\hline \multirow{2}{*}{ FPV } & P1 & ATGAGTGATGGAGCAGTTC & \multirow{2}{*}{ VP2 } & \multirow{2}{*}{ (1) } \\
\hline & $\mathrm{VP}$ & TTCTAGGTGCTAGTTGAG & & \\
\hline \multirow{4}{*}{$\begin{array}{l}\text { FcaGH } \\
\text { V-1 }\end{array}$} & FeGH-1f & CCTCCCAGGTTCARTWYGCMTAYGA & \multirow{4}{*}{$\mathrm{gB}$} & \multirow{4}{*}{ (6) } \\
\hline & FeGH-1r & CCGTTGAGGTTCTGAGTGTARTARTTRTAYTC & & \\
\hline & $\mathrm{FeGH}-2 \mathrm{f}$ & AAGATCAACCCCACNAGNGTNATG & & \\
\hline & FeGH-2r & GTGTAGTAGTTGTACTCCCTRAACATNGTYTC & & \\
\hline \multirow{2}{*}{ FeLV } & I2-xU3-F1 & ATTTCACAAGGMATGGAAAATTAC & \multirow{2}{*}{$\mathrm{U} 3$} & \multirow{2}{*}{$(20)$} \\
\hline & I2-xU3-R1 & TAGTTYAAATGAGGCGGAAGGT & & \\
\hline
\end{tabular}

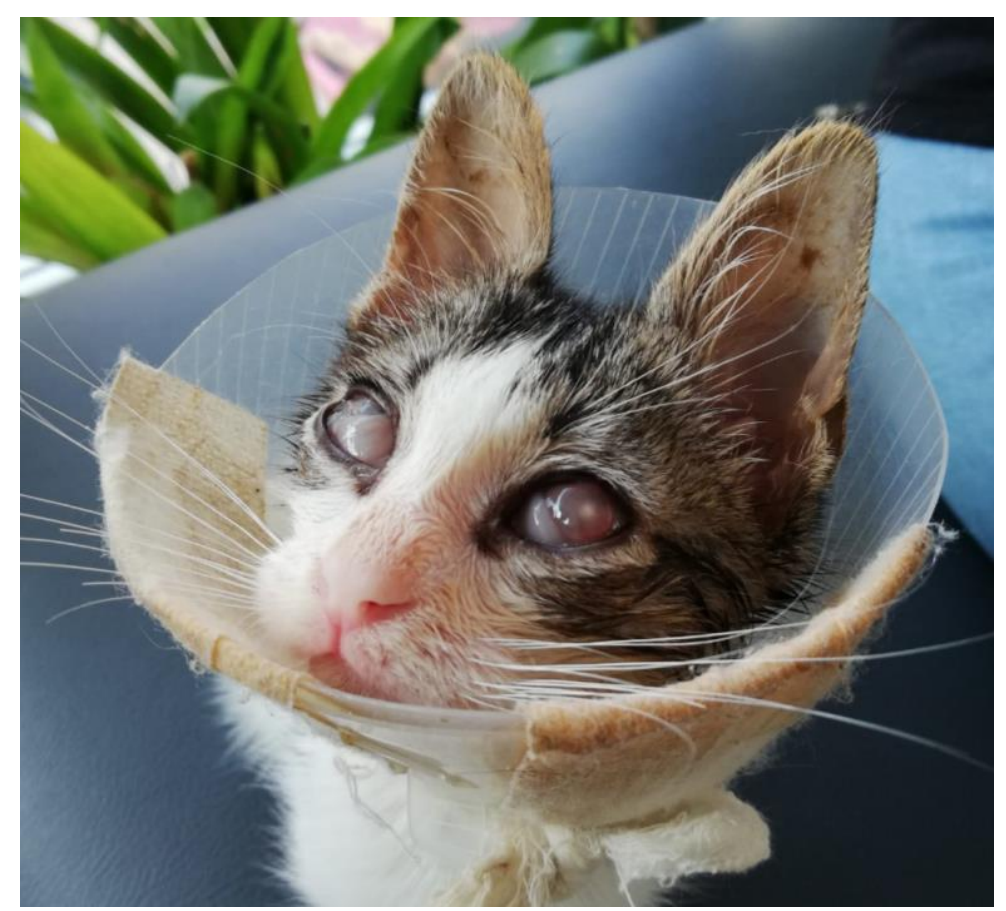

Figure 1. A FcaGHV-1 positive cat, named "Şirine", with the ocular disorders. The cat clinically displayed multisymptomatic ocular disorders including keratoconjunctivitis, symblepheron, and corneal ulcer. 


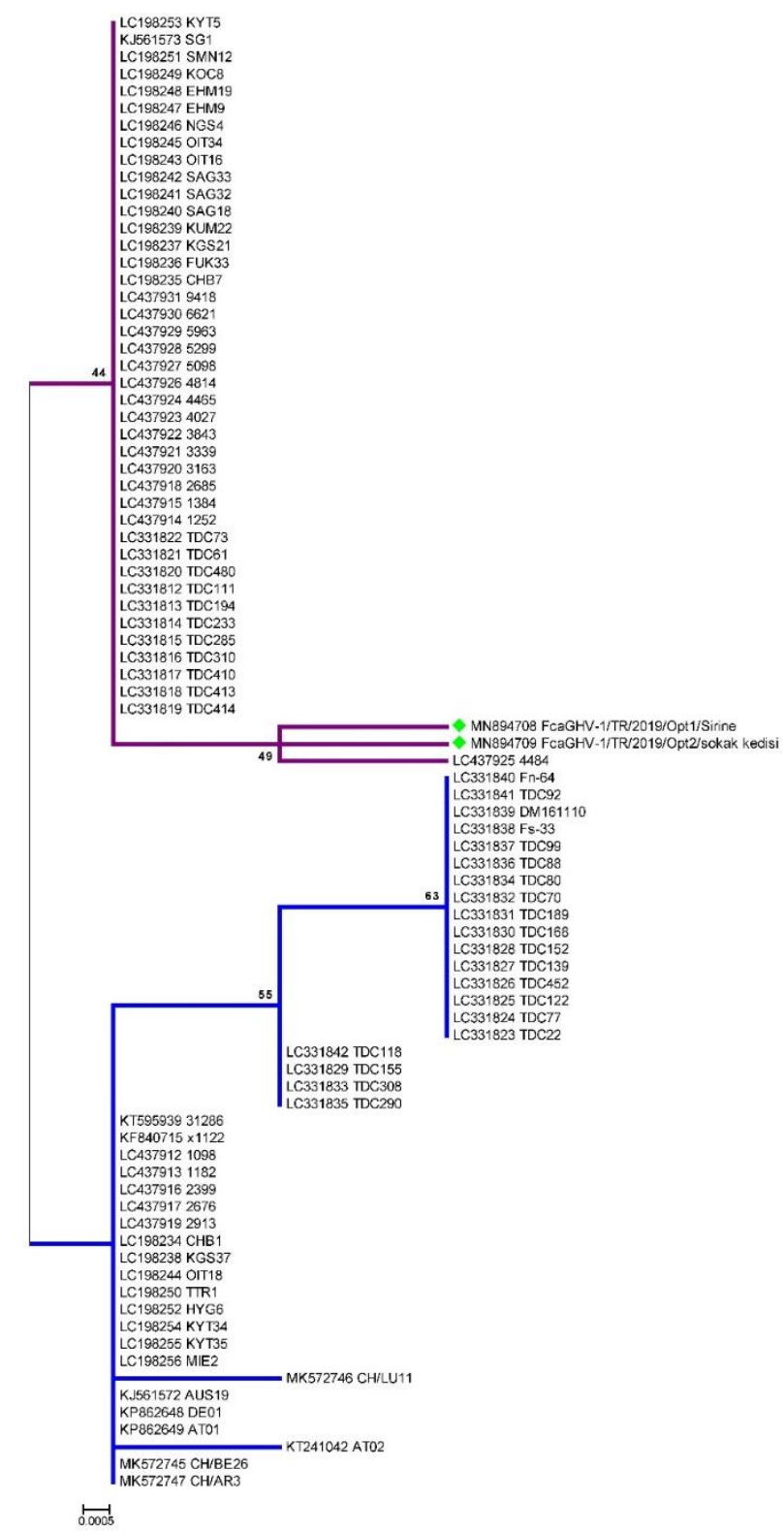

Figure 2. A maximum-likelihood tree of FcaGHV-1. The phylogenetic tree was constructed in MEGA X. Two main branches appeared which one is blue-colored and another is purple colored. The minor subgroup also appeared into purple-colored taxa in which our Turkish FcaGHV-1 sequences existed. Our sequences (GenBank Accession no. MN894708 and MN894709) were marked with "

\section{Discussion and Conclusion}

FcaGHV-1 is a newly discovered virus in cats (2). There is not a quite knowledge about the virus's pathogenesis mechanism and its reflection on clinic conditions $(2-4,15-18,24)$. Performed studies on FcaGHV-1 have mostly focused on its presence, prevalence, and distribution based on individual features (2-4, 15-18, 24). Accordingly, we, also, have investigated the presence of FcaGHV-1 and its clinical status by appeared symptoms in ocular tissues.

To conclusions of the other studies of FcaGHV-1 that have been performed so far, it has been considered this agent mostly infects to chronically FIV infected cats $(2,3,16-18)$. Potential immunodeficiency triggered by
FIV might be leading to the predisposition condition for FcaGHV-1 as similar to the pathogenesis mechanism of Human gammaherpesvirus and $\operatorname{HIV}(2,17,25)$. We have detected proviral DNA of FIV in same individuals infected by FcaGHV-1. It has strengthened the hypothesis that FIV infected cats are more predisposed to FcaGHV-1 up to five times $(2,25)$. Specifically, FcaGHV-1 infection is more likely to occur as ocular disorders in FIV infected cats. Perhaps, Equine herpesvirus -5 (EHV-5), a gammaherpesvirus causing ocular disease in equine, should to be paid attention as research on FcaGHV-1 pathogenesis strategy continues (21).

To our knowledge, this report exhibits the first molecular presence of FcaGHV-1 in Turkey. Other 
worldwide studies on FcaGHV-1 are available, however, presented molecular data in that studies to be evaluated are limited $(2-4,15-18,24)$. Nevertheless, we have found sequences of FcaGHV-1 in GenBank database and downloaded all overlapping gene regions of FcaGHV-1 with our sequences. As the different from other phylogenetic studies, we compared sequences FcaGHV-1 between themselves without sequences other genera of gammaherpesviruses. In the phylogenetic tree, two main clusters occurred which is seemed as purple and blue colored. With this appeared phylogenetic tree, "temporary" genotypes classification might be assumed as an effector for large-scaled and detailed molecular studies in the future. Molecular phylogenetic analysis revealed that Turkish FcaGHV-1 sequences drew a separated branch in purple colored genogroup in the phylogenetic tree. We have assessed alignment at amino acid levels why the possibility of genogroup has appeared. Two critical point changes at $530^{\text {th }}(\mathrm{G} \leftrightarrow \mathrm{R})$ and $584^{\text {th }}(\mathrm{T} \leftrightarrow \mathrm{I})$ amino acids of $\mathrm{gB}$ have been remarked and accordingly, it has been brought to mind that these changes might be responsible for genogroup diversification although our sequences covering to partial gB (ORF8) of FcaGHV-1 in BLAST (Figure 3). Nevertheless, this would be a speculative approach to decide genotyping or genogrouping. Detailed analysis such as next-generation sequencing (NGS) should be performed. After that, a more accurate decision would appear on genotyping.

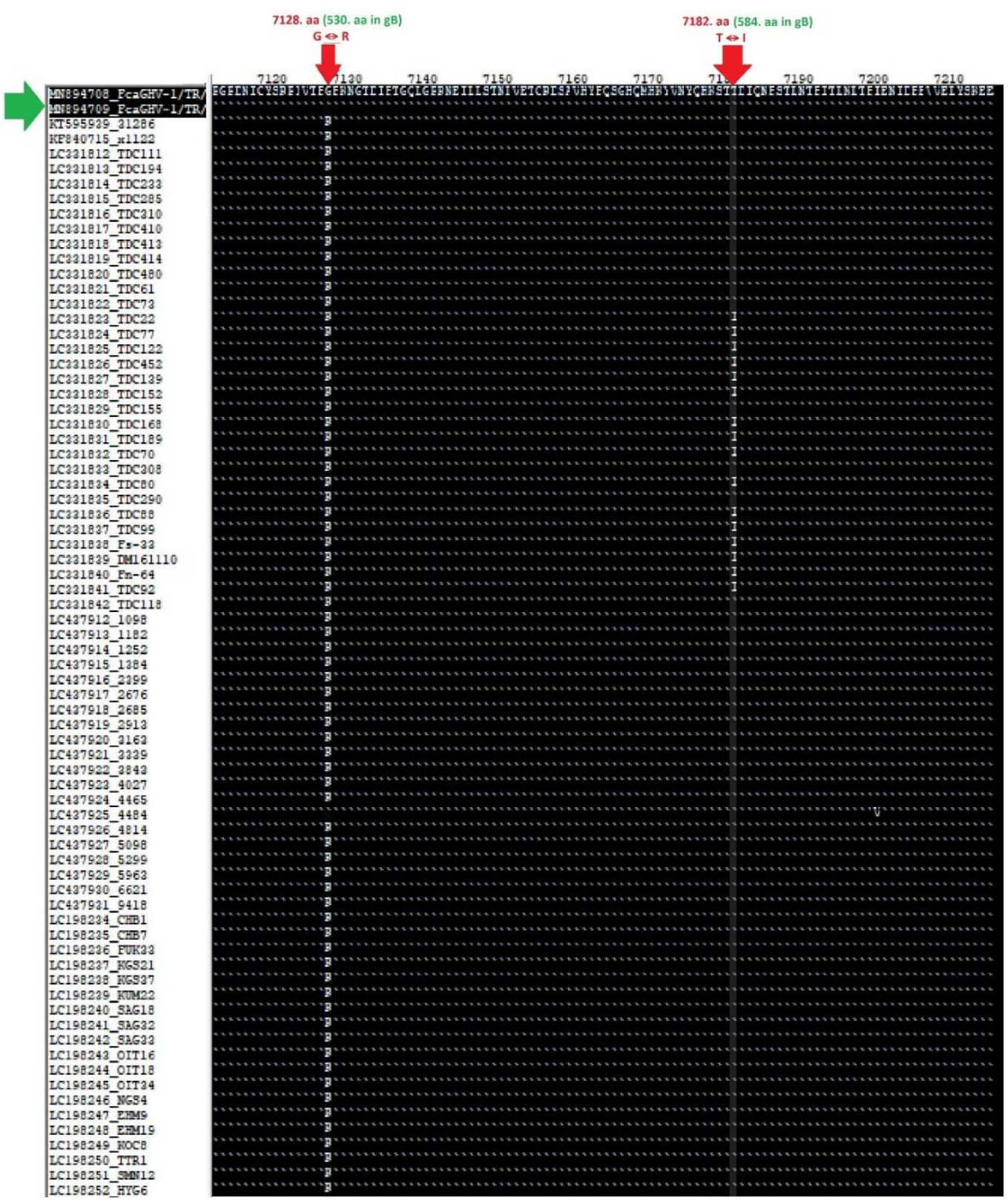

Figure 3. Amino acids changes on partial gB. Point mutations, where 530th $(G \leftrightarrow R)$ and 584th $(T \leftrightarrow I)$ amino acids, can be considered to lead phylogenetic diversity. 
We performed molecular detection and sequencing using conventional PCR primers previously described by Tateno et al. (24). More recently, Real-Time quantitative PCRs (RT-qPCR) have been performed into two different studies from Japan and Italy. RT-qPCR technique was claimed to be more reliable to diagnose FcaGHV-1 than conventional PCR in these studies. We have not yet been provided RT-qPCR facilities in our laboratory, therefore we could not compare outputs with mentioned studies. Detailed prevalence evaluation is not appropriate to compare data from other studies due to the minority of the population, however, only overall rates of presence of FcaGHV-1 could be paid attention. In our study, we found a positive rate to be $4.4 \%$ in the cohort. This result is not compatible with the majority of other prevalence studies which have reported between $6 \%$ and $23 \%(2,8,12,14$, $15,18,25)$. Only a few studies exhibited similar positivity rates, for example, Tateno et al. (23) and Caringella et al. (4) found the prevalence percentages as $1.3 \%$ (27/2659) and $1.01 \%$ (23/1738), respectively. Further analysis would be performed to evaluate both genetic status and both the prevalence of virus according to multivariate knowledge.

In sum, it has been thought by researchers that FcaGHV-1 causes a long-lasting and chronic infection, although it has not been exactly known how its molecular dynamics and pathology work. As related to this, performing only molecular studies on FcaGHV-1 is not enough to assess completely. We should consider in pointof-care, both molecular and serological studies should be performed. Data revealed from this application would leverage to elucidate the pathogenesis mechanism and interaction with immunity and other viruses.

This is the first report presenting molecular presence and phylogenetic of FcaGHV-1 in Turkey. Additionally, through our study, it was verified that FcaGHV-1 might have existed in cats with ocular disorders even though it had been declared being asymptomatic before. Regarding the conclusion of this study, it should be enlightened by further analysis, whether FcaGHV-1 in cats with ophthalmic symptoms were randomly detected in relevant tissues.

\section{Acknowledgements}

We thank the staff of Nova Veterinary Clinic, and cat owners' who provide the approval for this study.

\section{Financial Support}

This research received no grant from any funding agency/sector.

\section{Ethical Statement}

This study does not present any ethical concerns. All client approved and signed the informed consent form that allowing to use of collected samples as materials for this study. The publishing of this study was approved by the Local Ethical Committee for Experimental Animal of the Aydın Adnan Menderes University (No:64583101/2020/035).

\section{Conflict of Interest}

The authors declared that there is no conflict of interest.

\section{References}

1. Battilani M, Balboni A, Ustulin M, et al (2011): Genetic complexity and multiple infections with more Parvovirus species in naturally infected cats. Vet Res, 42, 1-9.

2. Beatty JA, Troyer RM, Carver S, et al (2014): Felis catus gammaherpesvirus 1; a widely endemic potential pathogen of domestic cats. Virology, 460-461, 100-107.

3. Beatty JA, Sharp CR, Duprex WP, et al (2019): Novel feline viruses: Emerging significance of gammaherpesvirus and morbillivirus infections. J Feline Med Surg, 21, 5-11.

4. Caringella F, Desario C, Lorusso E, et al (2019): Prevalence and risk factors for Felis catus gammaherpesvirus 1 detection in domestic cats in Italy. Vet Microbiol, 238, 108426.

5. Chomczynski P, Sacchi $\mathbf{N}$ (2006): The single-step method of RNA isolation by acid guanidinium thiocyanate-phenolchloroform extraction: Twenty-something years on. Nat Protoc, 1, 581-585.

6. Ehlers B, Dural G, Yasmum N, et al (2008): Novel mammalian herpesviruses and Lineages within the gammaherpesvirinae: cospeciation and interspecies transfer. J Virol, 82, 3509-3516.

7. Endo Y, Cho KW, Nishigaki K, et al (1997): Molecular characteristics of malignant lymphomas in cats naturally infected with feline immunodeficiency virus. Vet Immunol Immunopathol, 57, 153-167.

8. Ertl R, Korb M, Langbein-Detsch I, et al (2015): Prevalence and risk factors of gammaherpesvirus infection in domestic cats in Central Europe Herpes viruses. Virol J, 12, 146.

9. Hartmann K (2012): Clinical aspects of feline retroviruses: A review. Viruses, 4, 2684-2710.

10. Henzel A, Brum MCS, Lautert C, et al (2012): Isolation and identification of feline calicivirus and feline herpesvirus in Southern Brazil. Brazilian J Microbiol, 43, 560-568.

11. Kumar S, Stecher G, Li M, et al (2018): MEGA X: Molecular evolutionary genetics analysis across computing platforms. Mol Biol Evol, 35, 1547-1549.

12. Kurissio JK, Rodrigues MV, Taniwaki SA, et al (2018): Felis catus gammaherpesvirus 1 (FcaGHV1) and coinfections with feline viral pathogens in domestic cats in Brazil. Ciência Rural, 48, e20170480.

13. Lewin AC, Kolb AW, McLellan GJ, et al (2018): Genomic, recombinational and phylogenetic characterization of global feline herpesvirus 1 isolates. Virology, 518, 385-397.

14. Makundi I, Koshida Y, Endo Y, et al (2018): Identification of felis catus gammaherpesvirus 1 in 
Tsushima leopard cats (Prionailurus bengalensis euptilurus) on Tsushima Island, Japan. Viruses, 10, 378.

15. McLuckie AJ, Barrs VR, Smith AL, et al (2016): Detection of Felis catus gammaherpesvirus 1 (FcaGHV1) in peripheral blood $B$ - and T-lymphocytes in asymptomatic, naturally-infected domestic cats. Virology, 497, 211-216.

16. McLuckie AJ, Barrs VR, Lindsay S, et al (2018): Molecular diagnosis of Felis catus gammaherpesvirus 1 (FcaGHV1) infection in cats of known retrovirus status with and without lymphoma. Viruses, 10, 128.

17. McLuckie AJ, Barrs VR, Wilson B, et al (2017): Felis catus gammaherpesvirus 1 DNAemia in whole blood from therapeutically immunosuppressed or retrovirus-infected cats. Vet Sci, 4, 16.

18. Novacco M, Kohan NR, Stirn M, et al (2019): Prevalence, geographic distribution, risk factors and co-infections of feline gammaherpesvirus infections in domestic cats in Switzerland. Viruses, 11, 721.

19. Ravi M, Wobeser GA, Taylor SM, et al (2010): Naturally acquired feline immunodeficiency virus (FIV) infection in cats from western Canada: Prevalence, disease associations, and survival analysis. Can Vet J, 51, 271-276.
20. Roca AL, Nash WG, Menninger JC, et al (2005): Insertional polymorphisms of endogenous feline leukemia viruses. J Virol, 79, 3979-3986.

21. Rushton JO, Kolodziejek J, Tichy A, et al (2013): Detection of equid herpesviruses 2 and 5 in a herd of 266 Lipizzaners in association with ocular findings. Vet Microbiol, 164, 139-144.

22. Simons FA, Vennema H, Rofina JE, et al (2005): A $m R N A$ $P C R$ for the diagnosis of feline infectious peritonitis. J Virol Methods, 124, 111-116.

23. Stiles J (2014): Ocular manifestations of feline viral diseases. Vet J, 201, 166-173.

24. Tateno M, Takahashi M, Miyake E, et al (2017): Molecular epidemiological study of gammaherpesvirus in domestic cats in Japan. J Vet Med Sci, 79, 1735-1740.

25. Troyer RM, Lee JS, Vuyisich M, et al (2015): First complete genome sequence of Felis catus gammaherpesvirus 1. Genome Announc, 3, e01192-15.

26. Vögtlin A, Fraefel C, Albini S, et al (2002): Quantification of feline herpesvirus 1 DNA in ocular fluid samples of clinically diseased cats by real-time TaqMan PCR. J Clin Microbiol, 40, 519-523. 